GU J Sci, Part C, 6(1): 177-187 (2018)

Gazi Üniversitesi
Fen Bilimleri Dergisi
PART C: TASARIM VE TEKNOLOJI
dergipark.gov.tr/http-gujsc-gazi-edu-tr

\title{
Grafen Nanolevha Takviyesinin AlSi10Mg Alaşımının Mikroyapı ve Mekanik Özellikleri Üzerine Etkisi
}

\author{
Sinan KANDEMIR \\ İzmir Yüksek Teknoloji Enstitüsü, Mühendislik Fakültesi, Makine Mühendisliği Bölümü, 35430, Gülbahçe Urla/İZMïR
}

\begin{abstract}
$\ddot{\mathbf{O z}}$
Makale Bilgisi

Başvuru: $14 / 08 / 2017$

Düzeltme: 10/12/2017

Kabul: 26/12/2017

Anahtar Kelimeler

Grafen nanolevhalar Metal matrisli kompozitler Nanokompozitler

Alüminyum alaşımları

Bu çalışmada, birkaç grafen tabakasından oluşan, 100 nm'nin altında kalınlığa ve olağanüstü mekanik özelliklere sahip grafen nanolevhaların (GNL) endüstride sıkça kullanılan AlSi10Mg alaşımına katkısının mikroyapı ve mekanik özellikler üzerine etkisi incelenmiştir. Büyük yüzey alanı ve sahip oldukları yüksek yüzey enerjileri nedeniyle GNL'ların sıvı metaller içinde homojen olarak dağıtılması güçtür. GNL'ların sıv1 alüminyum alaşımına geçişi yarı-katı mekanik karıştırma ile matris içinde dağılımı ise ultrasonik proses ile gerçekleştirilmiştir. Dökülen kompozitlerin yapılan mikroyapı analizleri sonucunda, yüksek yoğunluktaki ultrasonik dalgalar ile GNL'ların aglomerasyonlarının önlenerek matris içinde göreceli olarak homojen dağıldığı ve matris-GNL'lar arasında iyi bir tutunma yüzeyinin elde edildiği gösterilmiştir. Gerçekleştirilen çekme deneylerinde, ağırlıkça \%0.25 GNL takviyesinin alaşımın mukavemetini önemli oranda arttırdığı tespit edilmiştir. Mukavemetteki iyileşme ağırlıklı olarak GNL'ların dislokasyonların ilerlemesinde bariyer vazifesi görmesine dayandırılmaktadır. Bu sonuçlar GNL takviyeli yüksek performanslı metal matrisli nanokompozitlerin seri imalata uygun olarak sıvı fazda üretilebilirliklerini göstermektedir.
\end{abstract}

Mikroyapı

Mekanik özellikler

Keywords

Graphene nanoplatelets Metal matrix composites Nanocomposites Aluminum alloys Microstructure Mechanical properties

\section{Effect of Graphene Nanoplatelets Reinforcement on the Microstructure and Mechanical Properties of AlSi10Mg Alloy}

\begin{abstract}
In this study, the effect of reinforcement of graphene nanoplatelets (GNPs that consist of a few graphene layers with a thickness of less than $100 \mathrm{~nm}$ and have extraordinary mechanical properties) on the microstructure and mechanical properties of AlSi10Mg alloy which is widely used in industry has been investigated. It is challenging to homogeneously disperse GNPs into liquid metals due to their large surface area and high surface energy. The GNPs have been incorporated into the liquid aluminum alloy with semi-solid mechanical mixing and dispersed into the matrix with ultrasonic processing. The microstructural analyses performed on the cast composites show that high intensity ultrasonic waves led to a relatively uniform dispersion of GNPs into the matrix by preventing their agglomeration, and a good bonding surface between the matrix and GNPs was obtained. In the tensile tests, it is seen that the addition of $0.25 \mathrm{wt} . \%$ GNPs has significantly increased the strength of alloy. The improvement in the strength is mainly attributed to the fact that GNPs act as barriers to the dislocation movement. The results show that the producibility of high performance GNPs reinforced metal matrix nanocomposites in liquid routes which is suitable for mass production.
\end{abstract}

\section{GÍRIŞ (INTRODUCTION)}

Endüstrinin, özellikle otomotiv endüstrisinin araç ağılıklarını düşürerek yakıt ekonomisine katkıda bulunmak ve $\mathrm{CO}_{2}$ salınımlarını azaltmak için hafif ve yüksek mukavemetli malzemelere olan talebi her geçen gün artmaktadır. $\mathrm{Bu}$ talep doğrultusunda, yüksek mukavemet/ağılık oranının yanı sıra yüksek süneklik ve iyi korozyon direncine sahip olması nedeniyle alüminyum alaşımları mühendislik uygulamalarında en çok kullanılan demirdışı malzemeler olagelmiştir. Ancak, alüminyum alaşımlarının çelik gibi metallere kıyasla düşük mukavemet göstermesi bu alaşımların kullanım alanlarını sınırlamaktadır. Literatürde yapılan çalışmalarda, ağırlıkça çok düşük miktarlarda (\%0.1-2.0) nano boyutlu seramik veya diğer sert partiküllerin hafif metallere ilavesinin, mikron boyutlu takviye elemanı 
içeren konvansiyonel metal matrisli kompozitlere (MMK) göre matrisin sünekliğinde kayda değer bir kayıp oluşturmadan mukavemeti önemli oranda arttırılabileceği gösterilmiştir [1-3]. Metal matrisli nano kompozitler (MMNK) olarak adlandırılan bu malzemelerin gelişimi MMK'lerde sıkça karşılaşılan düşük süneklik ve kırılma tokluğu problemlerinin aşılmasını sağlamıştır.

Hafif alaşımların mukavemetlendirilmesinde $\mathrm{Al}_{2} \mathrm{O}_{3}$ ve $\mathrm{SiC}$ gibi seramik nanopartiküllerin dışında, üstün mekanik ve fiziksel özelliklerinden dolayı karbon nanotüpler de birçok çalışmada kendisine yer bulmuştur [4,5]. Karbon nanotüplerin MMK'lerin mekanik özelliklerini önemli oranda geliştirmesine rağmen karbon nanotüplerin yüksek maliyeti ve yapısal bir deformasyona uğramadan matris içinde homojen dağılımındaki zorluklar bu malzemelerin pratik uygulamalardaki kullanımlarını sınırlamaktadır [6].

Son yıllarda karbon nanotüpler gibi karbon esaslı bir malzeme olan grafen geliştirilmiştir. Karbon atomlarının altıgen yapıda dizilmesiyle oluşturulan iki boyutlu malzeme grafen, eşsiz fiziksel özellikleri (Elastisite modülü: $\sim 1 \mathrm{TPa}$, Kırılma mukavemeti: $\sim 125 \mathrm{GPa}$ ve Isıl iletkenlik: $\sim 5000 \mathrm{~W} / \mathrm{mK}$ ) nedeniyle bilim dünyasının ilgisini çekmektedir [7-9]. Birkaç grafen tabakasından oluşan ve $100 \mathrm{~nm}$ 'nin altında bir kalınlığa sahip grafen nanolevhalar (GNL) endüstriyel olarak üretilebilmektedir. Tek katmanlı grafene kıyasla GNL'ların üretilmesi ve proses edilmesi daha kolaydır. Ayrıca, GNL'lar karbon nanotüplere göre daha ucuz ve kararlı bir yapıya sahiptir. Tüm bu özelliklerinden dolayı GNL'lar, karbon nanotüpler ve seramik nanopartiküllere alternatif ideal takviye elemanı olarak daha mukavemetli ve çok fonksiyonlu kompozitlerin üretilmesinde kullanılabilirler. GNL takviyesi ile polimer esaslı matrislerin mekanik ve fiziksel özelliklerinin önemli oranda geliştirildiğini gösteren çok sayıda araştırma varken, grafen takviyeli metal özellikle alüminyum matrisli nanokompozitlerin üretimi üzerine sınırlı sayıda deneysel çalışma mevcuttur $[10,11]$.

GNL takviyeli metal kompozitlerin üretilmesindeki temel zorluk, diğer nano boyutlu takviye elemanları gibi büyük yüzey alanı ve sahip oldukları yüksek yüzey enerjileri nedeniyle GNL'ların matris içinde kümeleşerek homojen olarak dağıtılamamasıdır [12]. Bu durumda kompozitte istenilen mekanik özellikler elde edilemeyebilir. Literatürdeki GNL içeren alüminyum matrisli nanokompozitlerin neredeyse tamamı toz metalurjisi yöntemi ile üretilmiştir [13-16]. Ancak, endüstride seri imalata uygunluk ve kompleks geometriye sahip komponentlerin ekonomik olarak üretilebilirlikleri açısından döküm yöntemine ihtiyaç duyulmaktadır. GNL’ların sıvı fazda alüminyuma takviyesinde, grafenlerin kümeleşme eğiliminin yanında alüminyum tarafından düşük ıslanabilirlikleri ve karbonun sıvı alüminyum ile reaksiyona girerek ara yüzeyde mekanik özellikleri zayıflatabilecek gevrek yapıya sahip $\mathrm{Al}_{4} \mathrm{C}_{3}$ filmi oluşturabilmesi de aşılması gereken teknik problemler olarak değerlendirilmektedir.

$\mathrm{Bu}$ çalışmanın motivasyonu; literatürde çok az sayıda bulunan sıvı fazda GNL takviyeli alüminyum mastrisli kompozit çalışmalarına yönelik katkıda bulunmaktır. Bu araştırmada temin edilen GNL'ların, sıv1 alüminyum alaşımında daha önce seramik nanopartikül takviyeli MMNK'lerin üretiminde de başarıyla kullanılan ultrasonik yöntem ile homojen olarak dağıtılması amaçlanmıştır. Ultrasonik yöntemde, yüksek yoğunluktaki ultrasonik dalgalar sıvı metalde kavitasyon baloncukları meydana getirmektedir ve eşik bir büyüklükten sonra bu baloncukların patlaması ile oluşan mikro sıcak noktaların GNL kümelerini ayırıp tüm matris boyunca homojen olarak dağıtabileceği öngörülmüştür. Ayrıca, GNL takviyesinin alüminyum alaşımlarının mikroyapı ile mekanik özellikleri üzerine etkilerinin sırasıyla ileri elektron mikroskop teknikleri ve çekme deneyleri vasıtasıyla incelenmesi de araştırmanın amaçları kapsamındadır. Ultrasonik yöntem ile birlikte GNL'ların alüminyum matrise yarı-katı karıştırma mekanizması ile beslenmesi araştırmanın özgün yönünü oluşturmaktadır. Zira, böyle sistematik bir çalışma bilgimiz dahilinde literatürde henüz raporlanmamıştır.

\section{MALZEME VE METOT (MATERIAL AND METHOD)}

Kompozit üretiminde matris malzemesi olarak Tablo 1'de kimyasal bileşimi verilen alüminyum AlSi10Mg alaşımı kullanılmıştır. Bu alaşımın tercih edilmesinin nedeni içeriğindeki \%10 silisyumun, karbon ve sivı alüminyum arasında meydana gelebilecek kimyasal reaksiyonu baskilayabilmesidir [17]. Takviye elemanı olarak ise piyasada mevcut, 50-100 nm arasında kalınlığa ve x,y ekseninde ortalama 5 $\mu$ m uzunluğa sahip GNL'lar kullanılmıştır. Bu GNL'ların taramalı elektron mikroskop (SEM) görüntüsü Şekil 1'de verilmiştir. 
GNL'lar aglomere olup eriyiğe nüfuz etmeden yüzeyde kalabilecekleri için direk olarak sıvı alüminyuma beslenmemiştir. GNL'ların matrise beslenmeden önce aglomerasyonunun önlenmesi için \%99 saflıkta, ortalama çapı $75 \mu$ m'den küçük boyutlarda alüminyum ve magnezyum tozları ile bilyalı öğütme işlemi gerçekleştirilmiştir. Magnezyum tozlarının kullanılmasındaki amaç; görece düşük yüzey gerilmesine sahip magnezyum eriyiğinin sıvı alüminyum alaşımının yüzey gerilimini azaltması, dolayısıyla GNL'ların 1slanabilirliklerini geliştirmesidir [18]. Bunun için $1 \mathrm{~g}$ GNL'lar ile 6'şar g alüminyum ve magnezyum tozları gezegen tipi bilyalı değirmende (Retsch PM 200) 2 saat ve 350 devir/dak.'da öğütülmüştür. Yaklaşık $9.5 \mathrm{~mm}$ çapındaki alümina bilyaların, toplam tozların ağırlığına oranı 4:1'dir. Her bir işlemde yaklaşık $6 \mathrm{~g}$ GNL içeren ögütülmüş toz karışımı, $250 \mathrm{MPa}$ basınç altında $30 \mathrm{~mm}$ çapında ve yaklaşık 4-5 mm yüksekliğinde tabletler oluşturacak şekilde preslenmiştir. Yaklaşık olarak tabletlerdeki GNL oranı ağırlıkça \% 7.7 olarak hesaplanmıştır.

Tablo 1. Kullanılan AlSi10Mg alaşımının kimyasal bileşimi, \% ağırlıkça

\begin{tabular}{|c|c|c|c|c|c|c|c|}
\hline $\mathrm{Al}$ & $\mathrm{Si}$ & $\mathrm{Fe}$ & $\mathrm{Cu}$ & $\mathrm{Mn}$ & $\mathrm{Mg}$ & $\mathrm{Zn}$ & $\mathrm{Ti}$ \\
\hline Kalan & 10.0 & 0.5 & 0.05 & 0.45 & 0.35 & 0.10 & 0.15 \\
\hline
\end{tabular}

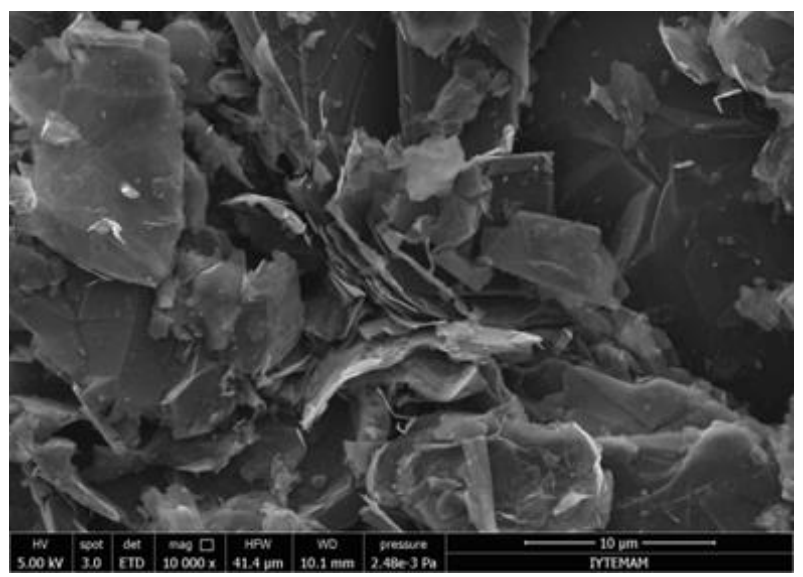

Şekil 1. Çalışmada kullanılan GNL'ların SEM görüntüsü.

Şematik deney düzeneği Şekil 2'de gösterilen GNL takviyeli nanokompozitin üretiminde ilk olarak yaklaşık $200 \mathrm{~g}$ AlSi10Mg alaşımı elektrikli ergitme ocağında ve grafit bir pota içinde $650{ }^{\circ} \mathrm{C}$ 'de ergitilmiştir. Bu sıcaklıktaki eriyik argon gazı altında 1000 devir/dak.'da grafitten yapılmış mekanik karıştırıcı ile karıştırılmaya başlanmış ve daha önce hazırlananan GNL'ları içeren iki tablet vorteks altında eriyiğe beslenmiştir. Tabletler mekanik karıştırma altında ergirken alaşımın sıcaklığının yarı katı sicaklığa $\left(580-590{ }^{\circ} \mathrm{C}\right)$ düştüğü ölçülmüştür ve yarı-katı sıcaklıktaki alaşım toplamda 15 dak. karıştırılmıştır. Yarı katı halde mekanik karıştırmanın, GNL'ların alaşım yüzeyine çıkmasını engelleyerek matriste dağılımlarını kolaylaştıracağ 1 öngörülmüştür. Mekanik karıştırıc1 çıkarıldıktan sonra alaşım 670 ${ }^{\circ} \mathrm{C}^{\prime}$ ye 1 sitılmıştır. Bu esnada, azami $700 \mathrm{~W}$ gücünde, $20 \mathrm{kHz}$ frekansta ultrasonik dalga üretebilen bir ünitenin (Q700 Qsonica, LLC) parçası olan ve titanyum alaşımından yapılmış ultrasonik prob sıvı alaşıma yüzeyden yaklaşık $15 \mathrm{~mm}$ derinliğe daldırılmıştır. Sıvı alaşım, GNL'ların homojen dispersiyonu için 650 ${ }^{\circ} \mathrm{C}$ 'de 15 dak. ve $80 \mathrm{~W}$ çalışma gücünde argon gazı altında ultrasonik prosese tabi tutulmuştur. Titanyumun $665^{\circ} \mathrm{C}$ üzerinde sıvı alüminyum ile reaksiyona girdiği bilindiği için ultrasonik proses 650 ${ }^{\circ} \mathrm{C}$ 'de gerçekleştirilmiştir. Prob çıkarıldıktan sonra alaşım $670{ }^{\circ} \mathrm{C}$ 'ye 1 șıtılmış ve çekme deneyi numulerinin elde edilmesi için ASTM B557M-10 standartına göre çelikten yapılmış bir kalıba dökülmüştür. Üretilen kompozitteki GNL oranı ağırlıkça \%0.25 olarak hesaplanmıştır. Ayrıca, GNL'ların mikroyapı ve mekanik özelliklere doğrudan etkisini gözlemlemek için GNL kullanılmadan sadece Al ve 
Mg tozları içeren tablet ilavesi ve kompozit üretiminde yukarıda belirtilen benzer proses parametreleri ile referans alaşımın dökümü gerçekleştirilmiştir.

Mikroyapı analizleri için dökülen parçalardan kesilen numuneler sıcak bakalite alınmış, geleneksel SiC zımparalama ve $1 \mu \mathrm{m}$ son parlatmanın ardından ultrasonik temizlemeye tabi tutulmuştur. Sadece tane boyutu analizi için numuneler Keller dağlayıcısı ile dağlanmıştır. GNL'lar ve matris arayüzeyini gözlemlemek ve aralarında oluşabilecek herhangi bir reaksiyon ürününe etki etmeme adına SEM ve geçirimli elektron mikroskobisi (TEM) analizleri için hazırlanan numunelerde dağlayıcı kullanılmamıştır. Mikroyapı karakterizasyonları, optik mikroskop (Leica DM2500 M), enerji dağılımlı x-1şını spektroskobi (EDX) analizi yapabilen SEM (FEI Quanta FEG 250) ve TEM (FEI Tecnai F30) cihazlarında gerçekleştirilmiştir. TEM örnekleri, hazırlanan numunelerden ultra mikrotom cihazı (Leica EM UC6) yardımı ile en fazla $100 \mathrm{~nm}$ kalınlığa sahip elektron geçirimli kesitlerin alınmasıyla oluşturulmuştur. Bu kesitler bakır gritlere yapıştırılarak TEM altında incelenmiştir.

Çekme testleri için silindirik numuneler, ASTM E 8/E 8M-08 standartlarına göre 6 mm çapında ve 20 mm ölçü uzunluğunda dökülen malzemelerden talaş kaldırılarak üretilmiştir. Malzemelerin çekme özellikleri üniversal bir test cihazı kullanarak $1 \mathrm{~mm} /$ dak. çekme hızında ve oda sıcaklığında belirlenmiştir. Nanokompozit ve referans alaşım için en az üç döküm yapılmış ve dökülen her bir örnekten en az üç numune test edilmiştir. Ortalama değerler standart sapmaları ile birlikte verilmiştir.

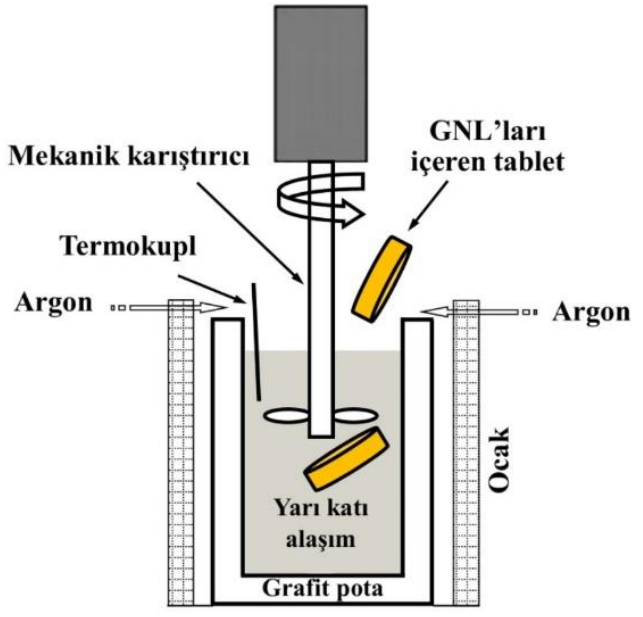

a)

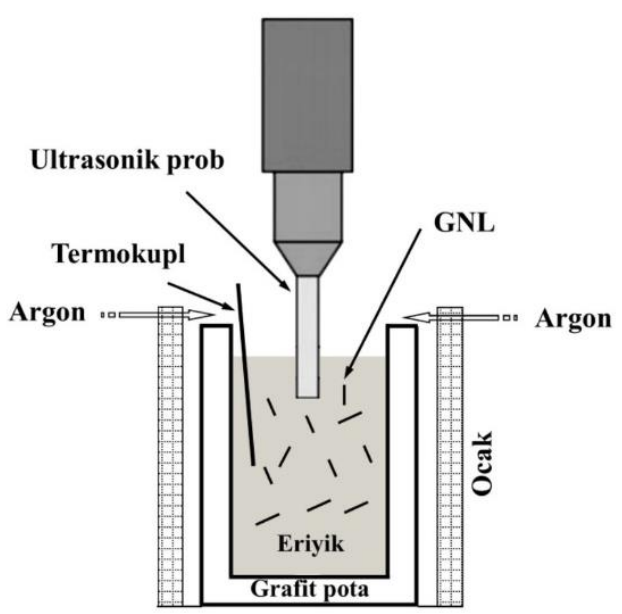

b)

Şekil 2. GNL takviyeli alüminyum matrisli nanokompozitlerin üretimi için oluşturulan deney düzeneğinin şematik resmi: a) Tabletlerin beslenmesi ile alaşımın yarı katı halde mekanik karışımı, b) Eriyik içinde GNL'ların ultrasonik dispersiyonu.

\section{DENEY SONUÇLARI VE TARTIŞMA (EXPERIMENTAL RESULTS AND DISCUSSION)}

Bilyalı değirmende ögütülen GNL, alüminyum ve magnezyum tozlarını içeren tabletlerden alınan bir kesitin Şekil 3'de verildiği gibi SEM ve elementel EDX haritalaması ile mikroyapı analizleri gerçekleştirilmiştir. SEM (Geri saçılım elektron, BSE) mikrografisi ve potansiyel olarak GNL'ların yerlerini işaret eden karbon (C) haritası, GNL'ların bilyalı ögütme ile kaba aglomerasyonlarının önlenerek tozlar arasında dağıtıldığını göstermektedir. Al ve $\mathrm{Mg}$ haritaları ise alüminyum ve magnezyum tozlarının tabletteki lokasyonlarını göstermektedir. Bununla birlikte, mikroyapıda GNL kümelerinin varlığını koruduğu gözlemlenmiştir.

Tabletlerin alüminyum alaşımı içinde mekanik ve ultrasonik karıştırma altında dağıtılmasıyla oluşturulan nanokompozit (AlSi10Mg/ ağ. \%0.25 GNL) ile AlSi10Mg referans alaşımına ait optik mikroskop görüntüleri Şekil 4'de gösterilmektedir. Optik mikroskop görüntülerinden GNL ilavesinin alüminyum 
alaşımının tane boyutunu önemli ölçüde küçülttüğü görülmektedir. ASTM E112 standartlarında verilen doğrusal kesiştirme metodu ile referans alaşım ve nanokompozitin ortalama tane boyutları sırasıyla $138 \pm 24 \mu \mathrm{m}$ ve $104 \pm 17 \mu \mathrm{m}$ olarak belirlenmiştir. Nanopartiküllere benzer olarak bu tane küçülmede GNL'ların çekirdeklenmede kataliz etkisi göstermiş olabileceği değerlendirilmektedir [19]. Bununla birlikte, mikroyapıda bazı bölgelerde primer $\alpha$-Al tanelerin küreselleştiği, dolayısıyla GNL ilavesinin mikroyapıyı kısmen rafine ettiği görülmektedir. Ancak, katılaşma parametrelerine bağlı olarak dentritik yapının tam olarak elemine edilemediği ve GNL'ların ötektik silisyumun morfolojisi üzerinde önemli bir modifikasyon oluşturmadığı gözlemlenmektedir. Bu modifikasyonun oluşmamasının sebebi; nispeten düşük konsantrasyondaki GNL'ların SEM görüntülerinde (Şekil 5) gösterildiği gibi daha ziyade primer $\alpha$ Al tane sınırları içinde yoğunlaşması, dolayısıyla ötektik bölgede önemli bir etki gösterememesi olarak ifade edilebilir.
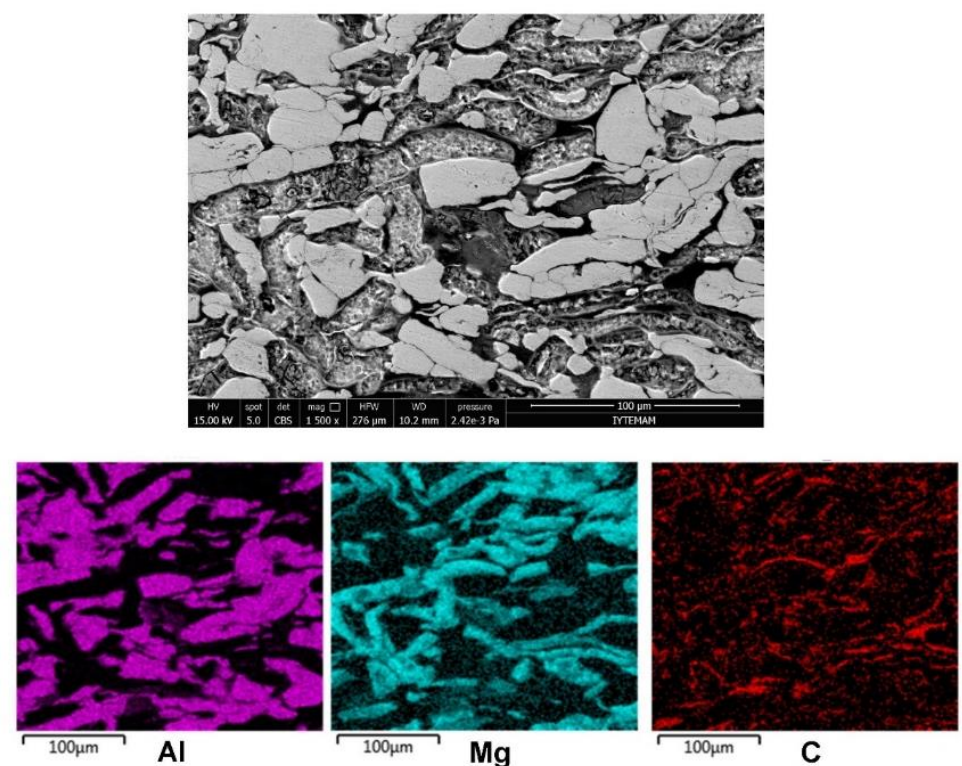

Şekil 3. GNL'lar $(C)$, alüminyum ( $A l)$ ve magnezyum $(M g)$ tozların içeren tabletin BSE görüntüsü ve EDX haritalamasi.
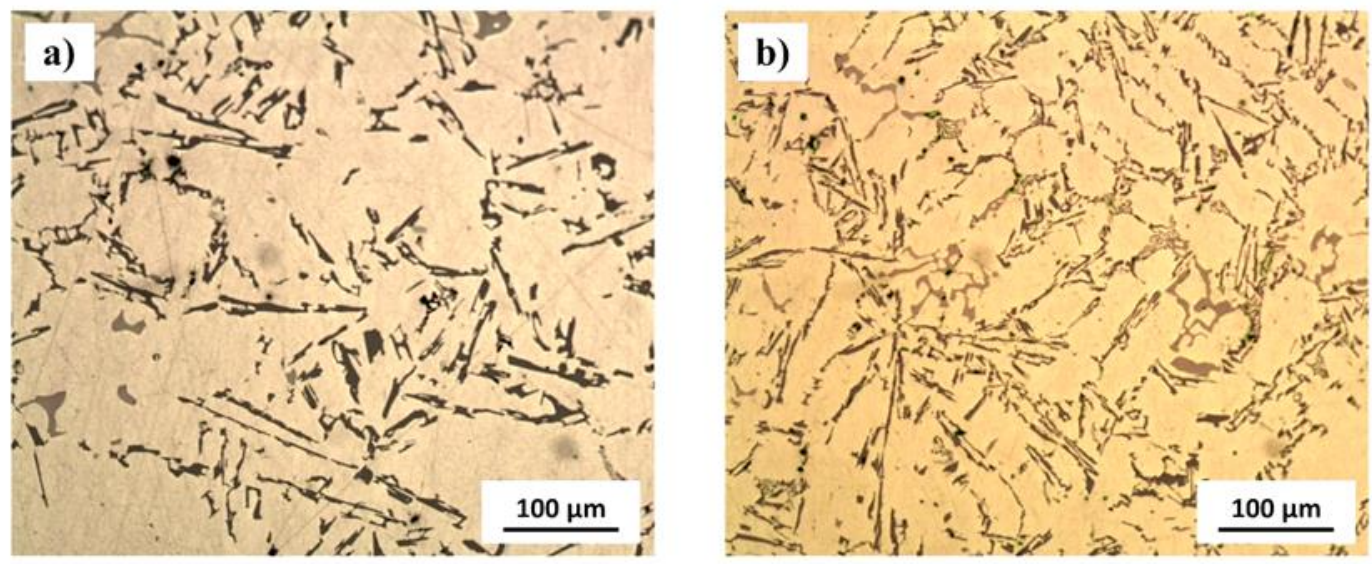

Şekil 4. a) Referans alaşım, ve b) üretilen AlSi $10 M g / \% 0.25$ GNL nanokompozitinin optik mikroskop görüntüleri.

Şekil 5'de ise GNL takviyeli alüminyum alaşımının farklı büyütmelerde ve ikincil elektron (SE) modundaki SEM görüntüleri verilmiştir. Şekil 5a'da görüldüğü gibi GNL'lar tüm matris boyunca göreceli olarak homojen şekilde dağıtılmıştır. Bu da bilyalı değirmende öğütülmüş $\mathrm{Al}$ ve $\mathrm{Mg}$ tozlarının, mekanik 
karıştırma ve ultrasonik proses kombinasyonu ile GNL'ların kümeleşmelerini önleyerek etkin bir şekilde matris içinde dağıtıldığını göstermektedir. Diğer göze çarpan nokta ise konvansiyonel MMK'lerdekinin aksine takviye elemanının sadece tane sınırlarındaki ötektik bölgede bulunmaması hem ötektik bölgede hem de çoğunlukla primer $\alpha-A l$ tane içlerinde (Şekil $5 b$ ve 5c) gözlemlenmesidir. Bu GNL'ların katılaşma sırasında mikron boyutlu takviye elemanları gibi tane sınırlarına baskılanmadığını göstermektedir. Ayrıca, matris içinde gözlemlenen potansiyel GNL'ların ortalama boyutunun 1 mikron ve mikron altı mertebelerde olduğu görülmektedir (Şekil 5d). Burada büyük olasılıkla başlangıçtaki GNL'ların yüksek enerjili bilyalı öğütme sırasında kırılmış olabileceği değerlendirilmektedir. Şekil 6'da Şekil 5d'de bulunan potansiyel bir GNL'nın matris ile karşılaştırmalı bölgesel EDX analizi verilmiştir. $\mathrm{Bu}$ analiz sonucunda matris ve takviye elemanı arasında gözlemlenen yüksek karbon konsantrasyonu GNL'ların matrise ilave edilmiş olabileceği fikrini desteklemektedir.

a)
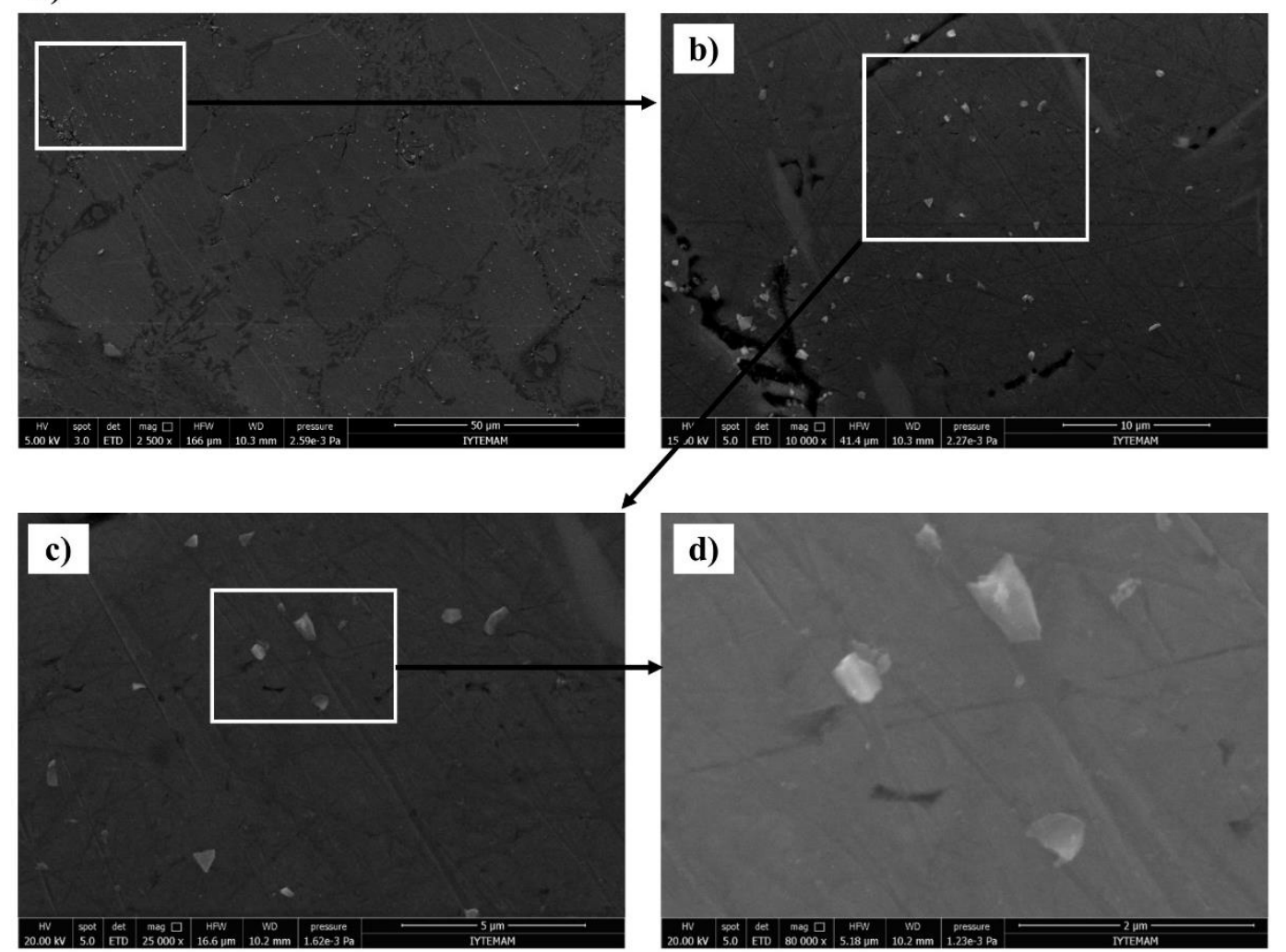

Şekil 5. AlSi10Mg/\%0.25 GNL nanokompozitinin farkl büyütmelerdeki SEM (SE) görüntüleri: a) 2500, b) 10000 , c) 25000 ve d) 80000 büyütme.

GNL'ların $\alpha$-Al matris içine gömüldügünden tam anlamıla emin olmak ve matris-takviye elemanı arayüzeyini incelemek için numunelerin Şekil 7'de verildiği üzere TEM analizleri gerçekleştirilmiştir. Şekil 7a'da birden fazla GNL tabakasından oluşan aglomerasyon bölgesi gözlemlenmiştir. Ayrıca, bu bölgelerde bazı GNL'lar köşelerinde kıvrımlı ve kırışı morfolojiye sahiptir. Dolayısıyla, bu kıvrımlı yapıların GNL'ların birbirine dolanmasını sağlayarak deaoglomerasyonlarını engellemiş olabileceği değerlendirilmektedir. Şekil 7a ve 7b'de GNL'ların sırasıyla yatay ve düşey olarak matrise gömüldüğü görülmektedir. Şekil 7c'de ise $\alpha$-Al matrise düşey yerleşmiş yaklaşık $50 \mathrm{~nm}$ kalınlık ve $300 \mathrm{~nm}$ genişliğe sahip bir GNL'nın $0.34 \mathrm{~nm}$ olarak ölçülen düzlemlerarası uzaklığı, GNL'ların alüminyuma başarı ile takviye edildiğini doğrulamaktadır. Yine Şekil 7c'de yüksek çözünürlükteki matris-GNL arayüzeyinde herhangi bir boşluk ya da reaksiyon sonucu olaşabilecek bir ara faz gözlenmemiştir. Herhangi bir kimyasal reaksiyon oluşmamasının nedeni olarak matris alaşımının içerdiği silisyum miktarı gösterilebilir. Ancak, bu durum sadece konvansiyonel MMK'lerde geçerli olabilir. Zira, mikron boyutlu karbon esaslı takviye elemanları alüminyum alaşımlarında tane sınırlarındaki ötektik bölgeye itilir. 
Dolayısıyla, ötektik bölgedeki silisyum karbonun sıv1 alüminyum ile reaksiyonunu baskılayabilir. Oysa, bu çalışmada GNL'lar sadece ötektik bölgede değil $\alpha$-alüminyum taneleri içinde de dağıtılmıştır. Bu durumda Eşitlik 1'e göre karbonun sıv1 alüminyum ile reaksiyona girmesi beklenir [20]. Eşitlik 2'ye göre ise sıcaklık $2455{ }^{\circ} \mathrm{C}(2728 \mathrm{~K})$ 'yi geçtiğinde $\mathrm{Al}_{4} \mathrm{C}_{3}$ oluşumu için serbest enerji sıfırdan büyüktür, dolayısıyla reaksiyon meydana gelmez. Literatürde ultrasonik kavitasyon sonucu oluşan mikro sicak noktaların $5000{ }^{\circ} \mathrm{C}$ 'ye kadar ulaşabildikleri rapor edilmiştir [21]. Dolayısıyla, ultrasonik proses sırasında açığa çıkan mikro-sıcak noktaların GNL'lar ile alüminyum arasında kimyasal reaksiyon oluşumunu önlemiş olabileceği değerlendirilmektedir. $\mathrm{Bu}$ sonuç $\mathrm{Al}_{4} \mathrm{C}_{3}$ oluşumunun önlenmesi bakımından Yan vd. [22]'nin ultrasonik proses ile karbon nanotüp takviyeli alüminyum kompozitlerinin üretimi üzerine olan çalışmasının sonuçları ile tutarlılık göstermektedir. Ayrıca, yüksek yoğunluktaki ultrasonik dalgaların karbon ile alüminyum eriyiği arasındaki ıslatma açısını düşürdüğü bilinmektedir [23]. Bu da GNL'lar ve matris arasında elde edilen temiz yüzeyi açıklamakta ve arayüzeyde iyi bir tutunmanın elde edildiğini göstermektedir.

$$
\begin{array}{r}
\frac{4}{3} A l(s)+C(k)=\frac{1}{3} A l_{4} C_{3}(k) \\
\Delta G_{1}^{0}=-89611+32.841 T .
\end{array}
$$
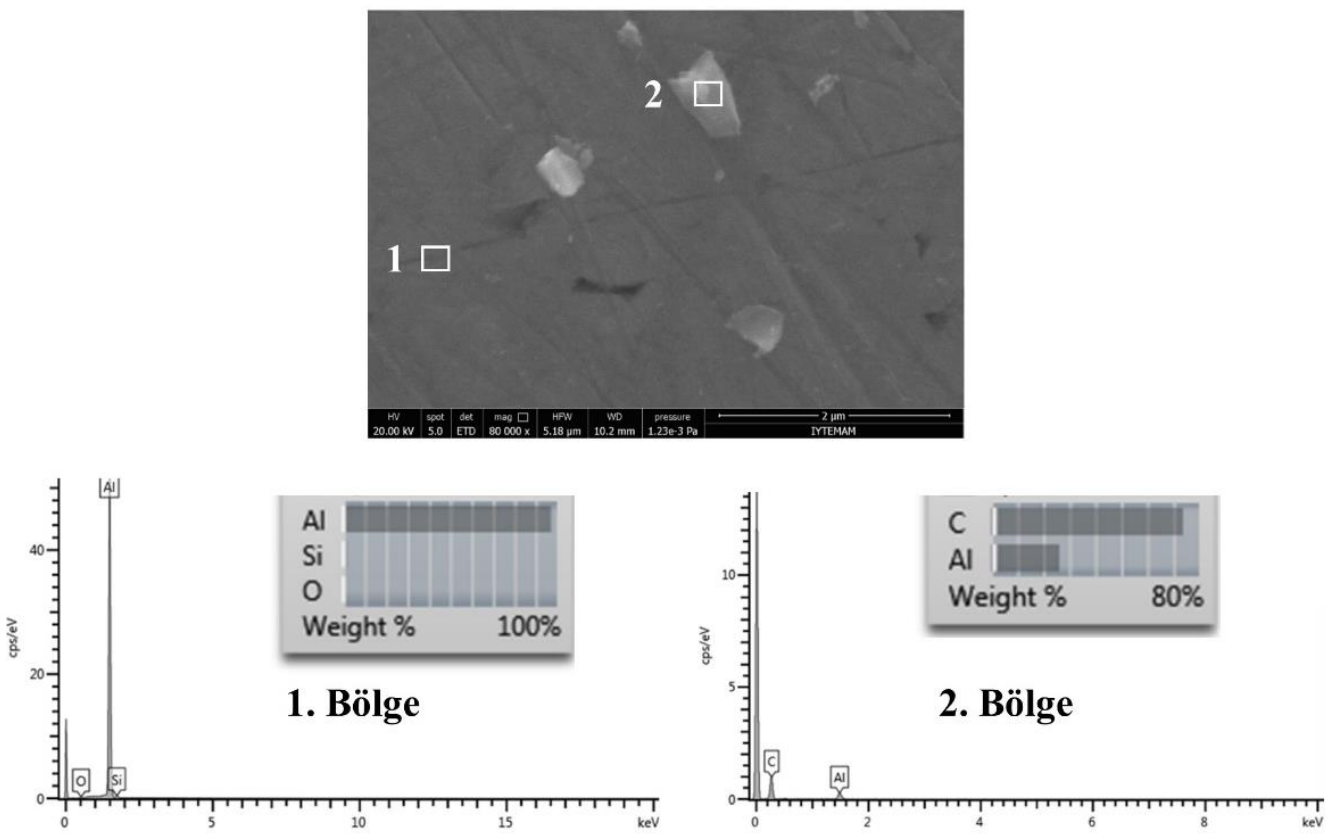

Şekil 6. Potansiyel GNL ile içinde bulunduğu $\alpha$-Al matrisin karşılaştırmalı EDX analizi.

Tablo 2'de AlSi10Mg referans alaşımı ile GNL takviyeli alaşımın çekme testlerinden elde edilen mekanik özellikleri karşılaştıılmaktadır. GNL takviyesinin, alaşımın \%0.2 akma ile çekme mukavemetini yaklaşık olarak sırasıyla \%15 ve \%22.5 oranında arttırdığı, bunun yanında süneklikte az da olsa bir düşüş meydana getirdiği görülmektedir. GNL'ların mukavemetin geliştirilmesindeki rolü, matris içinde yük taşıma kapasiteleri ve gerilim yoğunluğu oluşturarak dislokasyonların ilerlemesine iki boyutlu engel teşkil etmeleri ile açıklanabilir. Zira, alüminyum gibi yüzey merkezli kübik yapıya sahip metallerde tane küçültmenin, mukavemet artışında sınırlı etkisi olduğu bilinmektedir [24]. Matrise nispeten düşük konsantrasyonda (ă̆ırlıkça \%0.25) GNL ilavesi yapıldığ 1 için yük taşıma etkisinin de sınırlı olacağ 1 değerlendirilmektedir. Ayrıca, primer $\alpha$-Al matris $\left(23.6 \times 10^{-6}\left({ }^{\circ} \mathrm{C}\right)^{-1}[11]\right)$ ile GNL $\left(-8 \times 10^{-6}\left({ }^{\circ} \mathrm{C}\right)^{-1}[25]\right)$ arasındaki büyük 1sıl genleşme katsayısı farkı, oluşturduğu çok yönlü termal gerilmeler nedeniyle katılaşma sonunda plastik deformasyona sebebiyet verebilir. Bunun sonucunda, dislokasyon yoğunluğu 
artarak mukavemetin gelișmesine neden olabilir. Dolayısıyla temel mukavemetlendirme mekanizmasının, GNL'ların 1sıl genleşme farkından dolayı gerilme yoğunluğu oluşturması ve dislokasyon ilerlemesine engel teşkil etmiş olabileceği değerlendirilmektedir. Bununla birlikte, alüminyum ile GNL'lar arası elde edilen iyi tutunmanın (Şekil-7) da mukavemet artışında önemli bir yeri vardır. Süneklikteki kayıp ise mikroyapıda gözlemlenen ve matris içinde kısmi olarak aglomere olup kümeleşen GNL'lara dayandırılabilir. Çünkü, takviye elemanının kümeleştiği bölgeler genellikle çatlak oluşum ve ilerlemesine en yatkın bölgelerdir.
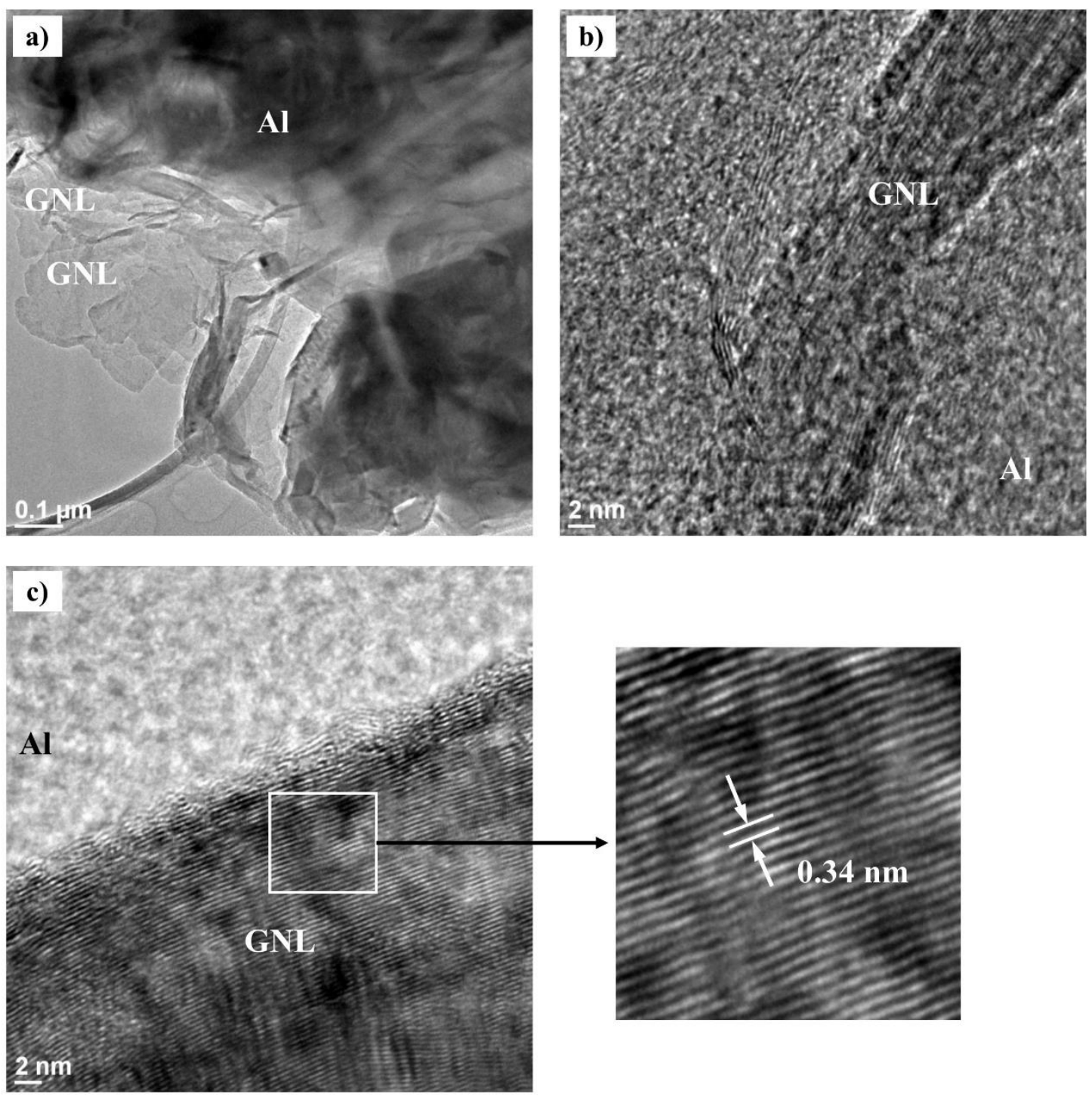

Şekil 7. AlSilOMg/\%0.25 GNL nanokompozitinde matrise gömülü GNL'larl gösteren TEM görüntüleri.

Tablo 2. AlSi10Mg referans alaşımı ve AlSi10Mg/\%0.25 GNL nanokompozitine ait örneklerin çekme testi değerleri

\begin{tabular}{|l|l|l|l|}
\hline Örnek & $\begin{array}{l}\text { \%0.2 akma mukavemeti } \\
(\mathrm{MPa})\end{array}$ & $\begin{array}{l}\text { Çekme mukavemeti } \\
(\mathrm{MPa})\end{array}$ & $\begin{array}{l}\text { Kopma anındaki } \\
\text { uzama (\%) }\end{array}$ \\
\hline AlSi10Mg referans alaşı1 & $123 \pm 4$ & $186 \pm 5.5$ & $3.6 \pm 0.7$ \\
\hline $\begin{array}{l}\text { AlSi10Mg/\%0.25 GNL } \\
\text { nanokompoziti }\end{array}$ & $142 \pm 7.5$ & $228 \pm 10$ & $3.3 \pm 0.9$ \\
\hline
\end{tabular}


Literatürde sifir boyutlu nanopartiküllerin ve tek boyutlu nanotellerin metal matrislerdeki mukavemetlendirme etkisini ortaya koyan birçok sayısal model geliştirilmiştir. Ancak, matrisde rastgele dağıtılan nano ölçekteki iki boyutlu ince levhaların mukavemetlendirmedeki etkisini hesaplayacak model geliştirmek zordur. $\mathrm{Bu}$ nedenle, MMNK'lerde rastgele dağıtılan iki boyutlu ince levhaların mukavemetlendirme mekanizmaları tam olarak ortaya konulamamışır [12]. Bu çalışmada bilgimiz dahilinde literatürde ilk defa GNL'lar, alüminyum alaşımı esaslı matrise yarı-katı karıştırma mekanizması ile beslenmiş, magnezyum ilavesi ile alüminyum esaslı matrisin GNL'ları 1slatabilirliği arttırılarak ultrasonik proses ile de GNL'ların görece etkin ve homojen olarak dağıtıldıkları ortaya konulmuştur. Ayrıca, ultrasonik proses sırasında açığa çıkan mikro-sıcak noktaların da GNL'lar ile alüminyum arasında potansiyel reaksiyon oluşumunu önleyerek yüksek mekanik özelliklerin elde edilmesi bakımından temiz bir arayüzey elde edildiği TEM analizleri ile gösterilmiştir. Alüminyum esaslı matriste görece homojen olarak dağılmış GNL'ları içeren böyle bir kompozit malzemenin sıvı fazda üretilmiş olması, iki boyutlu ince levhaların mukavemetlendirme mekanizmalarının anlaşılması ve bunların modellenmesine katkı sunabilir.

\section{SONUÇLAR (CONCLUSIONS)}

- Bu çalışma ile ağırlıkça $\% 0.25$ oranında $50-100 \mathrm{~nm}$ arasında kalınlığa ve x,y ekseninde ortalama $5 \mu \mathrm{m}$ uzunluğa sahip GNL'ların, yarı-katı mekanik karıştırma ile beslenmesi ve sıvı ultrasonik proses altında AlSi10Mg alaşımına başarılı bir şekilde takviyesi gerçekleştirilmiştir.

- Mikroyap1 analizleri, GNL takviyesinin alaşımın tane boyutunu küçülttüğünü ve yüksek yoğunluktaki ultrasonik dalgalar ile GNL'ların aglomerasyonlarının önlenerek matris içinde görece homojen olarak dağıtıldığını göstermiştir. Ayrıca, TEM çalışmaları GNL'ların matriste hem yatay hem de düşey olarak konumlandığını ve ara yüzeyde herhangi bir boşluk veya kimyasal reaksiyon oluşturmadan alüminyum matrise iyi tutunduğunu ortaya koymuştur. Yine de oluşmuş muhtemel reksiyon ürünlerinin tespitine yönelik çok sayıda örnekte arayüzeyin daha ayrıntılı analizi, gelecek araştırma konusu olarak yüksek çözünürlüklü TEM (HRTEM) vasıtasıyla gerçekleştirilebilir.

- GNL takviyesinin, alaşımın \%0.2 akma ile çekme mukavemetini yaklaşık olarak sırasıyla \%15 ve $\% 22.5$ oranında arttırdığı, bunun yanında süneklikte yaklaşık $\% 8$ oranında bir azalma meydana getirdiği görülmüştür. Mukavemetteki iyileşme, GNL'ların matris ile 1sıl genleşme katsayısı farkından dolayı gerilim yoğunluğu oluşturması ve dislokasyonların ilerlemesine engel teşkil etmesine bağlanırken, süneklikteki düşüş çatlak oluşuma hassas matriste gözlemlenen kısmi GNL kümelenmelerine dayandırılmıştır.

- $\mathrm{Bu}$ araştırma, GNL'ların sıvı fazda alüminyum alaşımlarına takviyesinde ekstrüzyon ve haddeleme gibi ikincil bir prosese gerek duyulmadan seri imalata uygun GNL takviyeli MMNK'lerin üretilebilirliklerini ortaya koymuştur.

\section{TEŞEKKÜR (ACKNOWLEDGMENTS)}

$\mathrm{Bu}$ çalışma, TÜBİTAK tarafindan 3501 programı kapsamında 214M091 nolu proje ile desteklenmiştir. SEM ve TEM cihazlarının kullanımı için yazar sırasıyla İzmir Yüksek Teknoloji Enstitüsü Malzeme Araştırma Merkezi (IYYTE MAM) ile Bilkent Üniversitesi Ulusal Nanoteknoloji Araştırma Merkezi (UNAM)'ne teşekkür eder. Yücel Aydoğan'a deney düzeneklerinin hazırlanmasındaki katkılarından dolayı ayrıca teşekkür edilmektedir. 


\section{KAYNAKLAR (REFERENCES)}

[1] Y. Yang, J. Lan, X. Li, Study on bulk aluminum matrix nano-composite fabricated by ultrasonic dispersion of nano-sized $\mathrm{SiC}$ particles in molten aluminum alloy. Materials Science and Engineering A, 380: 1-2 (2004) 378-383.

[2] S. F. Hassan, M. Gupta, Effect of nano- $\mathrm{ZrO}_{2}$ particulates reinforcement on microstructure and mechanical behavior of solidification processed elemental Mg. Journal of Composite Materials, 41: 21 (2007) 2533-2543.

[3] A. Mazahery, H. Abdizadeh, H. R. Baharvandi, Development of high-performance A356/nano- $\mathrm{Al}_{2} \mathrm{O}_{3}$ composites. Materials Science and Engineering A, 518: 1-2 (2009) 61-64.

[4] H. Kwon, M. Estili, K. Takagi, T. Miyazaki, A. Kawasaki, Combination of hot extrusion and spark plasma sintering for producing carbon nanotube reinforced aluminum matrix composites. Carbon, 47: 3 (2009) 570-577.

[5] S. Bakshi, D. Lahiri, A. Agarwal, Carbon nanotube reinforced metal matrix composites - A review. International Materials Reviews, 55: 1 (2010) 41-64.

[6] E. Neubauer, M. Kitzmantel, M. Hulman, P. Angerer, Potential and challenges of metal-matrixcomposites reinforced with carbon nanofibers and carbon nanotubes. Composites Science and Technology, 70: 16 (2010) 2228-2236.

[7] A. K. Geim, K. S. Novoselov, The rise of graphene. Nature Materials, 6: (2007) 183-191.

[8] C. Lee, X. Wei, J. W. Kysar, J. Hone, Measurement of the elastic properties and intrinsic strength of monolayer graphene. Science, 321: 5887 (2008) 385-388.

[9] A. A. Balandin, S. Ghosh, W. Bao, I. Calizo, F. Teweldebrhan, F. Miao, C. N. Lau, Superior thermal conductivity of single-layer graphene. Nano Letters, 8: 3 (2008) 902-907.

[10] S. J. Yan, S. L. Dai, X. Y. Zhang, C. Yang, Q. H. Hong, J. Z. Chen, Z. M. Lin, Investigating aluminum alloy reinforced by graphene nanoflakes. Materials Science and Engineering A, 612: 1 (2014) 440-444.

[11] M. Rashad, F. Pan, A. Tang, M. Asif, Effect of graphene nanoplatelets addition on mechanical properties of pure aluminum using a semi-powder method. Progress in Natural Science: Materials International, 24: 2 (2014) 101-108.

[12] L. Chen, H. Konishi, A. Fehrenbacher, C. Ma, J. Xu, H. Choi, H. Xu, F. E. Pfefferkorn, X. Li, Novel nanoprocessing route for bulk graphene nanoplatelets reinforced metal matrix nanocomposites. Scripta Materialia, 67: 1 (2012) 29-32.

[13] S. F. Bartolucci, J. Paras, M. A. Rafiee, J. Rafiee, S. Lee, D. Kapoor, N. Koratkar, Graphenealuminum nanocomposites. Materials Science and Engineering A, 528: 27 (2011) 7933-7937.

[14] J. Wang, Z. Li, G. Fan, H. Pan, Z. Chen, D. Zhang, Reinforcement with graphene nanosheets in aluminum matrix composites. Scripta Materialia, 66: 8 (2012) 594-597.

[15] R. Pérez-Bustamante, D. Bolaños-Morales, J. Bonilla-Martínez, I. Estrada-Guel, R. MartínezSánchez, Microstructural and hardness behavior of graphene-nanoplatelets/aluminum composites synthesized by mechanical alloying. Journal of Alloys and Compounds, 615: (2014) 578-582.

[16] J. L. Li, Y. C. Xiong, X. D. Wang, S. J. Yan, C. Yang, W. W. He, J. Z. Chen, S. Q. Wang, X. Y. Zhang, S. L. Dai, Microstructure and tensile properties of bulk nanostructured aluminum/graphene composites prepared via cryomilling. Materials Science and Engineering A, 626: (2015) 400-405. 
[17] J. C. Lee, J. Y. Byun, S. B. Park, H. I. Lee, Prediction of Si contents to suppress the formation of $\mathrm{Al}_{4} \mathrm{C}_{3}$ in the $\mathrm{SiC}_{\mathrm{p}} / \mathrm{Al}$ composite. Acta Materialia, 46: 5 (1998) 1771-1780.

[18] N. Eustathopoulos, J. C. Joud, P. Desre, J. M. Hicter, The wetting of carbon by aluminium and aluminium alloys. Journal of Materials Science, 9: 8 (1974) 1233-1242.

[19] M. P. De Cicco, L. S. Turng, X. Li, J. H. Perepezko, Nucleation catalysis in aluminum alloy A356 using nanoscale inoculants. Metallurgical and Materials Transactions A, 42: 8 (2011) 2323-2330.

[20] L. Ci, Z. Ryu, N. Y. Jin-Phillipp, M. Rühle, Investigation of the interfacial reaction between multiwalled carbon nanotubes and aluminum. Acta Materialia, 54: 20 (2006) 5367-5375.

[21] K. S. Suslick, Y. Didenko, M. M. Fang, T. Hyeon, K. J. Kolbeck, W. B. McNamara, M. M. Mdleleni, M. Wong, Acoustic cavitation and its chemical consequences. Philosophical Transactions of the Royal Society of London A, 357: 1751 (1999) 335-353.

[22] H. Yan, Z. Huang, H. Qui, Microstructure and mechanical properties of CNTs/A356 nanocomposites fabricated by high-intensity ultrasonic processing. Metallurgical and Materials Transactions A, 48: 2 (2017) 910-918.

[23] Y. L. Li, T. G. Zhou, Achieving Al melt/carbon and Al-Ti melts/carbon interfaces wetting via ultrasonic couple processing. Metallurgical and Materials Transactions A, $44: 7$ (2013) 3337-3343.

[24] D. J. Lloyd, Particle reinforced aluminium and magnesium matrix composites. International Materials Reviews, 39: 1 (1994) 1-23.

[25] D. Yoon, Y. W. Son, H. Cheong, Negative thermal expansion coefficient of graphene measured by Raman spectroscopy. Nano Letter, 11: 8 (2011) 3227-3231. 